\title{
Static Game Research on Incomplete Information of Internet Governance- Based on Game of the Chinese Government Regulators and Internet Companies
}

\author{
Meishi Jiang ${ }^{1}$, Wenyi He ${ }^{1}$, Yu Cao ${ }^{1, *}$, Wei Yin ${ }^{1}$, Mengjiao Guo ${ }^{2}$, Guizhen Wang ${ }^{3}$, Liangwei Chen ${ }^{1}$ \\ and Yulin Wang ${ }^{1}$
} ${ }^{I}$ School of Public Administration, Central South University, Changsha Hunan 410083, China, ${ }^{2}$ School of Business, Cen-
tral South University, Changsha Hunan 410083, China; ${ }^{3}$ School of Foreign Languages, Xiangtan University, Xiangtan
Hunan 410005, China

\begin{abstract}
Internet economy is a new economic phenomenon generated in information network era and has become an essential element of economic development and social operation. Due to the characteristics of height credit, virtualization of economic forms and changing patterns in the Internet economy, the massive illegal criminality also has produced in different forms at the same time, which necessitates government regulation. Based on the static game model with incomplete information, this paper makes a game analysis of the Chinese government regulators and the Internet economy enterprises. The analysis indicates that the effectiveness of government regulation depends on the lowering cost of supervision and inspection, the increase of penalties for violations, as well as the improvement of government regulation positive impacts on the society and consumers.
\end{abstract}

Keywords: Government regulation, internet economy, static game model with incomplete information.

\section{INTRODUCTION}

In the era of information network, the Internet economy has become a new engine of economic development, and the new economic development model has produced huge economic and social benefits. The iGDPs (the ratio of the Internet economy to GDP) of all countries are increasing year by year and China's iGDP has reached the level of the world's leading countries, as shown in Fig. (1). The Internet economy promotes the continuous change of economic system, industrial structure and economic and social development of all countries. Nowadays the Internet represented by e-commerce, instant messaging, search engines and online games is pushing economic development to a new level and a variety of new business models will spring up constantly in the future. Under such a rapid development trend of the Internet economy, the profit-driven behaviors of various Internet companies form the breeding ground for massive illegal criminality in different forms such as unfair competition in network environment, violation of the legitimate rights and interests of consumers, consumers' information asymmetry issues, network security issues and illegal Internet economy. Therefore, the supervision of government departments on the Internet economy enterprises has to be established to address adverse selection and market failures caused by asymmetric information between Internet companies and consu mers.
Currently, most academic researches on Internet governance model focus on two aspects, namely qualitative and quantitative research methods. In the first aspect, the following achievements have been obtained: Philip J. Weiser (2009) proposed that the establishment of co-regulatory model of public institutions and private sectors be the best strategy for Internet governance to move forward [1]; John Palfrey (2010) described four stages of Internet governance restricted by technology and use, including "open Interne", "access denied", "access controlled" and "access contested" [2]; Luo Jing (2008) introduced the main direction and several typical ways and their legislative exploration in the current international network supervision, and put forward some proposals on the regulatory model of the Internet in China combined with the present situation of the network management in our country; Zhang Liya (2009) discussed the reasons why network management problems occur, difficulties in monitoring the behaviors of network operators and how to strengthen the regulation on network operation. In terms of quantitative research method, Zhang Zhigang (2002) analyzed the problems of the supervision and administration of Internet information resources from the perspective of game theory and pointed out the important significance of government regulation and consumers' supervision [5]; Xu Qionglai (2008) established the signal transfer model of internet trade, KMRW reputation model, and incomplete information static game theory and proposed many polices such as decreasing the information asymmetry in Internet environment in his doctoral dissertation "Game theory research on the loss of internet trade trust under asymmetric information"[6]. Li Gang (2011) analyzed the root and harm- 


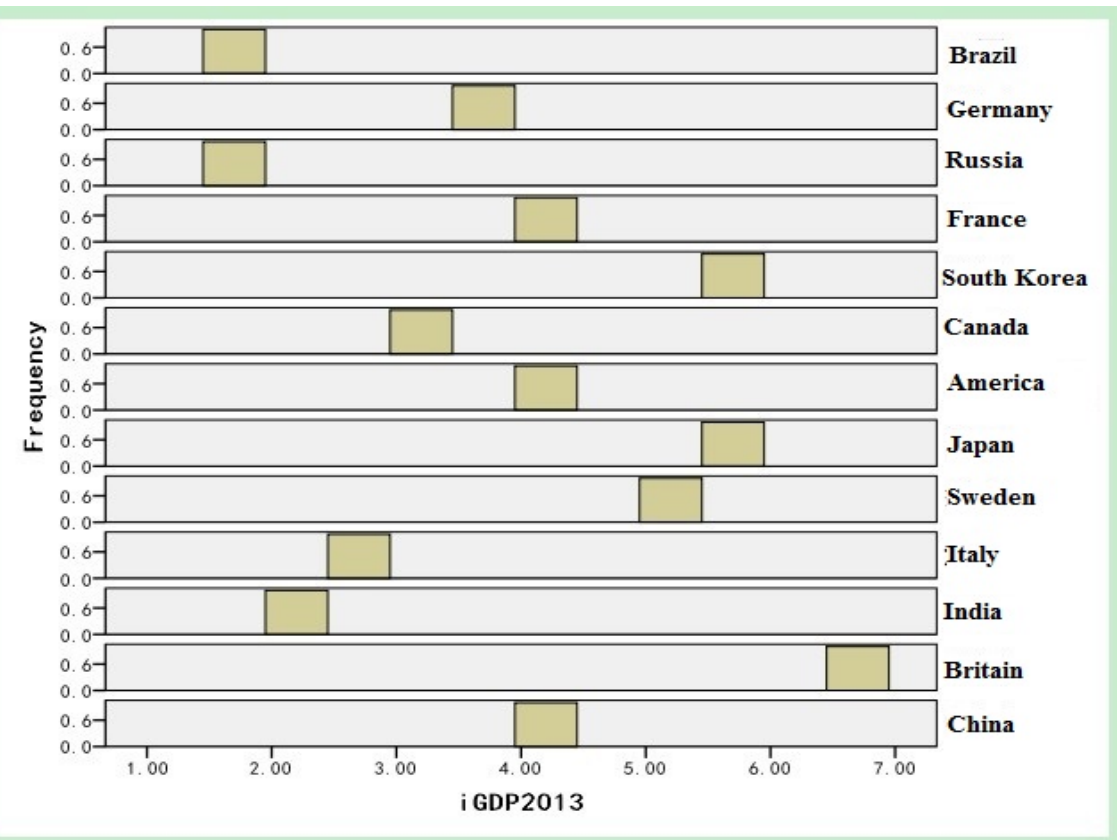

Fig. (1). iGDP2013. Source: Mckinsey global institute.

fulness of vulgar content generalization in Internet, established three static game models with complete information among ICP, IPP, Internet users and the government-led regulators on the basis of the principle of the game theory, revealed the key findings of Internet vulgar content regulation by exploring equilibrium model and put forward corresponding suggestions [7]. Jian Jie (2012) set up the evolutionary game model between the governments and the network operators in the network business activities, analyzed the stability condition of the two sides of the game and revealed behavioral characteristics of both sides and their impact on the steady state [8].

This paper makes a study of the regulatory subject and object, namely government oversight agencies and network operators. It utilizes the game theory to analyze the factors between the two sides and puts forward some suggestions on management of enterprises' illegal behaviors in the Internet economy. Employing the Game Theory into the research of government regulation of the Internet economy companies, can not only analyze the law of mutual restraint and interaction of both sides in decision-making process, derive reasonable results and illustrate the relevant practical problems, but also can guide the rational decisions of policy-making parties, and help governments and institutions with organizational and management functions to develop reasonable policies and rules.

\section{THE GAME MODEL BETWEEN GOVERNMENT REGULATORS AND INTERNET COMPANIES}

This paper mainly employs the Supervisory Game model proposed in the book "Game Theory" written by Drew Fudenberg and Jean Tirole, the winners of the 2014 Nobel Prize in Economics, to analyze the illegal acts of Internet companies and the government regulation issues. The following presents the hypothesis and construction of the game model as well as the analysis of the game behavior.

\subsection{Model Hypothesis}

(1) Game participants: the game participants include Internet companies related to the Internet economy and government regulators.

(2) Strategies available to two parties of the game: Internet companies can legally or illegally conduct business activities; government regulators can take measures to monitor them or not.

(3) The assumption of rational economic man: both government regulators and Internet companies are rational economic men and are seeking to maximize their economic benefits.

(4) Internet companies can predict the ways of government regulation.

(5) Benefits of both parties of the game: In order to ensure the objectivity of the results of the game, letters will be employed to represent benefits of both parties. In the game, the costs and their expected returns of Internet companies and government regulators can be estimated and is public information. Their behaviors are known to each other, that is, if enterprises break the law, their violations will be examined and punished by the government regulators. The strategy combinations of both parties are shown in Table 2.

\subsection{The Construction of the Game Model and Behavior Analysis}

\subsubsection{Constructing the Game Model}

In terms of the benefits and costs of network operators, the Internet companies as a game player can legally conduct business activities in the market economy to obtain normal returns (called $\mathrm{R}$ ) and the normal operating cost is called $\mathrm{C}$. In order to obtain excess returns, some enterprises are likely to conduct illegal business practices, then they will get the benefit called $\mathrm{R} *$, including normal profits and non- 
Table 2. The strategy combinations of both parties.

\begin{tabular}{|c|c|c|c|}
\hline \multirow{3}{*}{ Network operators } & \multicolumn{3}{|c|}{ Government Regulators } \\
\cline { 2 - 4 } & & regulatory & non-regulatory \\
\cline { 2 - 4 } & legal & legal, regulatory & legal, non-regulatory \\
\cline { 2 - 4 } & illegal & illegal, regulatory & illegal, non-regulatory \\
\hline
\end{tabular}

Table 3. The Payoff Matrix of Internet companies and government regulators.

\begin{tabular}{|c|c|c|c|}
\hline \multirow{4}{*}{ Internet companies } & & Government Regulators & $\begin{array}{c}\text { Non-regulatory } \\
(1-\mathrm{q})\end{array}$ \\
\cline { 2 - 4 } & & Regulatory (q) & $\mathrm{R}^{*}-\mathrm{C},-\mathrm{S}$ \\
\cline { 2 - 4 } & $\begin{array}{c}\text { Legal } \\
(\mathrm{p})\end{array}$ & $\mathrm{R}^{*}-\mathrm{C}-\mathrm{M}, \mathrm{M}-\mathrm{B}+\mathrm{S}$ & $\mathrm{R}-\mathrm{C}, 0$ \\
\cline { 2 - 4 } & Illegal & R-C, -B & \\
\hline
\end{tabular}

legitimate excess profits, and at this time the operating costs are still called $\mathrm{C}$ (not including the penalty). If in the process of the Internet enterprises conducting an illegal business, the government regulators take regulatory measures and discover their illegal activities, the Internet companies will need to pay a penalty $\mathrm{M}$.

For the benefits and costs of government regulators, the government regulators as the other party of the game can take regulatory or non-regulatory strategies to network operators. If the government regulators take regulatory measures, they need to pay the relevant costs B, including labor costs, technology costs, etc. These measures will take positive effects (called S) on the society, such as protecting the legitimate interests of consumers, maintaining social order and enhancing the government' image. If the regulatory measures are taken in the process of enterprises breaking the law, the penalty $\mathrm{M}$ of the enterprises will become the government's revenue. If no regulatory measures are taken, those enterprises will not pay the extra cost, which, however, will bring too many negative influences to consumers and the society. When consumers' rights and interests are not guaranteed, their trust in the government will drop and then bring about a series of negative effects (called $-\mathrm{S}$ ).

The government regulators choose their own strategy in a random probability. The decision-making model of accumulating alternative policies in a certain probability distribution is one of "the mixed strategies". This paper assumes that the probability of illegal business of enterprise is $p$ and that of legitimate business is $1-p$; the probability of government regulators taking regulatory measures is $\mathrm{q}$ and that of nonregulatory measures will be $1-\mathrm{q}$. In summary, the Payoff Matrix of Internet companies and government regulators is shown in Table $\mathbf{3}$.

The first principle for the two parties in the game is not to let the other know or guess their own choice and therefore the decision-making must be random. The second one is that the probability of each policy they choose must be the exact one the other exploits. In other words, the other party cannot gain the upper hand in the game by a targeted policy. The probabilities $\mathrm{p}$ and 1-p must make the expected benefit of government's regulatory measures equal to that of its nonregulatory ones, i.e.

$$
: \cdots M-B+S £ @ \mathrm{p}+(-B) \times(1-p)=(-S) \times \mathrm{p}+0 \times(1-\mathrm{p})
$$

Therefore, $p=\frac{B}{M+2 S} 1-p=\frac{M+2 S-B}{M+2 S}$

Similarly, the probabilities $\mathrm{q}$ and 1-q also must make the expected benefit of Internet companies' legal business equate that of their illegal one, i.e.

Therefore,

$$
q=\frac{\mathrm{R}^{*}-\mathrm{R}}{\mathrm{M}}
$$

$(\mathrm{R} *-\mathrm{C}-\mathrm{M}) \times \mathrm{q}+(\mathrm{R} *-\mathrm{C}) \notin 1-\mathrm{q} £(\mathrm{R}-\mathrm{C}) \times \mathrm{q}+(\mathrm{R}-\mathrm{C}) \times(1-\mathrm{q})$

$1-q=\frac{M-\mathrm{R}^{*}+\mathrm{R}}{\mathrm{M}}$

In this case, when Internet companies choose legal or illegal business activities with the probability of $\left(\frac{B}{M+2 S}\right.$, $\left.\frac{M+2 S-B}{M+2 S}\right)$ and the government regulars make a random choice between regulatory and non-regulatory measures with the probability of $\left(\frac{\mathrm{R}^{*}-\mathrm{R}}{\mathrm{M}}, \frac{M-\mathrm{R} *+\mathrm{R}}{\mathrm{M}}\right)$ neither party can change the probability of their own through random selection to improve their expected benefits, so this mixed strategy combination is stable, which is the only mixed strategy Nash equilibrium in this game.

On the premise of the hypothesis of "economic man", the paper makes an analysis of the game model in the following. Assuming that the Internet enterprises' expected return is U,

$$
U=\left(\mathrm{R}^{*}-\mathrm{C}-\mathrm{M}\right) \mathrm{pq}+(\mathrm{R} *-\mathrm{C}) \mathrm{p}(1-\mathrm{q})+(\mathrm{R}-\mathrm{C})(1-\mathrm{p}) \mathrm{q}+
$$

$(\mathrm{R}-\mathrm{C})(1-\mathrm{p})(1-\mathrm{q})$ 
Based on the rational economic man hypothesis, enterprises will pursue the maximization of profit, namely the maximization of $\mathrm{U}$. Calculating the derivative of the above function $\frac{\mathrm{d} U}{d \mathrm{p}}=0$, the $\mathrm{q}$ can be shown as $q=\frac{\mathrm{R}^{*}-\mathrm{R}}{\mathrm{M}}$. In other words, when $q=\frac{\mathrm{R}^{*}-\mathrm{R}}{\mathrm{M}}$, the Internet enterprises will obtain the maximum return.

In the same way, suppose the expected return of government regulators is $\mathrm{W}$,

$$
W=(\mathrm{M}-\mathrm{B}+\mathrm{S}) \mathrm{pq}+(-\mathrm{S}) \mathrm{p}(1-\mathrm{q})+(-\mathrm{B})(1-\mathrm{p}) \mathrm{q}+0 \mathrm{pq}
$$

The government regulators also look for the maximized profits, or the maximized W. Calculating the derivative of the above function $\frac{\mathrm{d} U}{d \mathrm{p}}=0$, the result will be $p=\frac{B}{M+2 S}$. That is, when $p=\frac{B}{M+2 S}$, the expected return of the government regulators will be the largest.

\subsubsection{Analyzing the Game Behavior}

The only mixed strategy Nash equilibrium in this game is ( $p=\frac{B}{M+2 S}, q=\frac{\mathrm{R} *-\mathrm{R}}{\mathrm{M}}$ ). The purpose of the study is to learn about how to reduce $p$, the probability of Internet enterprises to carry out illegal operation, and improve q, the probability of government regulators taking measures. The above analysis shows that we can make an adjustment of the government regulatory costs $\mathrm{B}$, the positive effects $\mathrm{S}$ of government regulation, the penalty $M$ of business illegal acts, the $\mathrm{R}^{*}$ of enterprises' illegal profits and the $\mathrm{R}$ of normal profits. Concrete analysis is as follows:

1. $\mathrm{M}$ is in the position of the denominator, assume $\mathrm{M}$ is invariant.

To reduce the probability of Internet enterprises to carry out illegal operation $\mathrm{p}$, we can choose to increase $\mathrm{S}$ or reduce B. In terms of government regulation, the more excess illegal profits the enterprises gain, the higher the probability of the government regulation is.

\section{Assume $\mathrm{M}$ is a variant.}

In the formula $p=\frac{B}{M+2 S}$, it is found that the change of $\mathrm{B}$ will have a bigger effect than that of $\mathrm{M}$ and $\mathrm{S}$. To a certain extent, if we want to reduce the probability of enterprises carrying out illegal operation, the best way is to reduce the supervisory cost other than increase punishment or positive effects. If the illegal business profits $R^{*}$ of enterprises increases constantly, they will take risks to pursue the excess enterprise profit and then the q also will increase correspondingly. Once the government takes regulatory measures, the enterprise will certainly face huge fines. So, to reduce excess profits of enterprise illegal business at that time can put an end to their illegal business behaviors.

\section{CONCLUSION AND POLICY RECOMMENDATIONS}

According to the above analysis of the game model of Internet companies and government regulators, in order to help government agencies play a better regulatory role in the Internet economy at this stage, the following measures could be adopted:

Firstly, due to the great impact of monitoring expenditures on the government's regulatory behaviors, we should reduce the cost of government agencies to regulate Internet companies. The Internet economy has the characteristics of an open environment, virtualized objects, hidden actions and diversified forms, which puts forward higher request to the government regulation. Therefore, the first problem the government regulators should solve is how to make low-cost regulation in the high requirement. The government can develop specialized software for network operators conduct regulation and effectively manage the websites and online activities related to its regulatory objects. By this way, it can enhance regulatory efficiency and reduce labor costs.

Secondly, the government should increase the punishment level for those illegal operations of Internet companies. The punishment can be intangible and tangible. On the one hand, we can strengthen public propaganda and supervision on Internet companies with illegal behaviors through the Internet to bring them tremendous loss of reputation and image. On the other hand, we should increase the penalties for illegal enterprises in terms of money, making their operation costs far outweigh non-legitimate excess profits, and then this unlawful phenomenon can be put an end to a certain extent.

Thirdly, the government regulation will take positive impacts on the society and consumers. The impacts will not easily change and should be enhanced constantly. First of all, we can promote and offer support to the government supervisory behaviors through the Internet, television, newspapers and other platforms, and increase dramatically the positive image of the government as a service sector. Then, government regulators should be given proper rewards and subsidies for their incentives to improve their initiative in supervision work.

Finally, the regulation of the Internet economy cannot totally depend on our government. On the one hand, we can enhance public awareness of the importance of regulating unlawful acts to form an effective model of the whole people involving in the regulation. On the other hand, we can learn from the regulatory systems of the United States, Britain and Japan---- the coordinated regulatory system dominated by government regulators and supplemented with industry associations and other NGOs. In the United States, a variety of professional Internet industry associations will take the initiative to develop conventions and standards of public recognition in the industry to strengthen the industry norms and self-discipline; in the UK, the Internet Watch Foundation(IWF) was set up in 1996 as an effective complement to government regulation; in Japan, the Japanese government gave guidance and invited representatives of the internet economy to found the Internet Self-Discipline Organization at first. After the organization began to work, the government quit and decentralized power to non-governmental or- 
ganizations to supervise the network economy and the implementation of industry self-regulation [9].

\section{CONFLICT OF INTEREST}

The authors confirm that this article content has no conflict of interest.

\section{ACKNOWLEDGEMENTS}

Declared none.

\section{REFERENCES}

[1] P. J. Weiser, "The Future of Internet Regulation," The Select Works of Phil Weiser, vol. 16, no.9, pp. 1-55, 2009.

[2] J. Palfreyt, "Four Phases of Internet Regulation," Social Research, vol. 77, no. 3, pp. 11-22, 2010.

[3] J. Luo, "The Comparison of Regulation Patterns of Internet Abroad Forum of World Economics \& Politics," vol.56, pp.117-121, 2008.
[4]L. Zhang, and G. Xiao, "Standard Guidance Promotes Healthy Development of the Internet Economy Study on China Administration for Industry \& Commerce," vol. 59, pp. 32-34, 2009.

[5] Z. Zhang, "Game Analysis of Supervision and Administration over Internet Information Resource," Journal of University of Shanghai For Science and Technology, vol. 244, pp. 349-353, 2002.

[6] Q. Xu, "Game Theory Research on the Loss of Internet Trade Trust under Asymmetric Information," Beijing University of Posts and Telecommunications , 2008

[7] G. Li, and Q. Song, "Game Analysis on China's Internet Vulgar Content RegulationManagement Review," vol. 10, pp.77-82, 2011

[8] J. Jian, "Evolutionary Game---Theoretic Analysis of Network Market Regulator and Network Traders," Journal of Information, vol. 317, pp. 172-176, 2012.

[9] D. Liang, Ouyang Shengzeng, Lin Gongfu. "The Analysis of Problems for the Industry and Commerce in the Network Market Regulation and Countermeasures Sanming Daily," 2011.

[10] S. Xie, "Economic Game TheoryShanghai," Fudan University Press, 2010.

Supported by the "the Internet and digital publishing communication"consulting project 2012 of the Chinese Academy of Engineering.

Received: September 16, 2014

Revised: December 23, 2014

Accepted: December 31,2014

(C) Jiang et al.; Licensee Bentham Open.

This is an open access article licensed under the terms of the Creative Commons Attribution Non-Commercial License (http://creativecommons.org/licenses/by-nc/3.0/) which permits unrestricted, non-commercial use, distribution and reproduction in any medium, provided the work is properly cited. 